\title{
Navigating the ethical maze of genomics in Canada's military
}

\author{
M J S Beauvais $\odot,{ }^{1}$ B M Knoppers, ${ }^{1,2}$ C Boscarino ${ }^{3}$
}

\section{INTRODUCTION}

Genomic research and its applications are no longer reserved for individuals and families with rare diseases. The military has begun to take a more active interest in the real-world insights genomics can give. For example, genomics, combined with other health and -omics data, can further our understanding human performance under exigent conditions of heat, stress, sleep deprivation and more. Most notably, this has been the case with the US Air Force, whose MilSeq project is among the forerunners in examining the clinical, scientific and ethical issues that incorporating genomics into the military poses. ${ }^{1}$

Defence Research and Development Canada, a branch of the Canadian Armed Forces (CAF), has also begun incorporating genomics into their research activities. In this article, we are the first to examine the bioethical and legal norms that regulate human genomic research conducted by the CAF. We first detail the bioethical context of military genomics in Canada. We then outline issues relating to consent, privacy, genetic discrimination and the return of results. We conclude by reflecting on the increased protections Canadian law and ethics can offer to service members who participate in genomic research.

\section{BIOETHICAL CONTEXT}

For genomic research with the CAF, there are two overarching concerns in understanding relevant ethical, legal and social issues. First is that bioethical norms largely have the civilian population in mind. ${ }^{2}$ Research with human participants undertaken under the auspices of the CAF follow the Tri-Council Policy Statement: Ethical Conduct for Research Involving Humans (TCPS2). ${ }^{3}$ Second

\footnotetext{
${ }^{1}$ Centre of Genomics and Policy, Department of Human Genetics, Faculty of Medicine, McGill University, Montreal, Quebec, Canada

${ }^{2}$ Canada Research Chair in Law and Medicine, Montreal, Quebec, Canada

${ }^{3}$ Defence Research and Development Canada, Government of Canada, Toronto, Ontario, Canada
}

Correspondence to M J S Beauvais, Centre of Genomics and Policy, Department of Human Genetics, Faculty of Medicine, McGill University, Montreal, QC H3A OG1, Canada; michael.beauvais@mcgill.ca is that scholarship on the ethical and legal dimensions of military biomedical research does not take the Canadian context into account.

\section{Consent}

There is significant harmonisation between civilian Canadian and international norms regarding what informed participant consent entails. ${ }^{4}$ Despite similarities, we highlight here three aspects that merit special consideration for genomic research with service members: information-giving obligations, voluntariness and withdrawal.

\section{Information-giving obligations}

As in the civilian context, information related to the purposes, uses and storage conditions of the biosamples and associated genomic data will be communicated to the participant. ${ }^{5}$ Even though the risk is minimal, further information related to both the potential to be reidentified from deidentified data sets, as well as the safeguards put in place to prevent reidentification, for example, prohibitions on reidentification by researchers. For the military, however, further information should be given regarding the potential future uses of genomic data. If information generated during research may be used to determine a service member's fitness for service, this should be disclosed, allowing for participants to appreciate the reasonably foreseeable consequences of their participation in research.

\section{Voluntariness}

Additional safeguards are further merited for service members participating in research to ensure the voluntary nature of consent. ${ }^{6}$ In particular to the Canadian military, the TCPS2 highlights the possibility of undue influence arising where a commanding officer recruits participants. ${ }^{5}$ An additional safeguard may then include a commanding officer specifying that the decision to participate is at the service member's own choosing and without consequences for service. Other safeguards could include approaching junior recruits individually rather than as a group and providing superiors with the research protocol. $^{7}$ Such actions may curtail peer pressure and mitigate concerns that superiors would unfavourably judge the decision to participate, respectively. To avoid even the appearance of bias in collaborative research with other countries' militaries, reimbursement for inconveniences incurred through research participation should only come from the country to which the service member owes their allegiance.

\section{Withdrawal}

Debates have centred around the effect of leaving the armed forces and the potential effects this has on the continued storage and use of biosamples and data. ${ }^{89}$ The decision to leave the military per se should, in most cases, bring an end to prospective sample and data collection. Given the silence of the TCPS 2 on this topic, and taking into account the importance of maintaining the robustness of samples and data as a collective research resource, we believe that a proportionate balance is best struck by informing participants during the informed consent process that if they wish to have their samples and/or data destroyed after leaving the military, that they must either (1) indicate this desire at the time of consenting or (2) notify the research team on leaving. This approach respects participant autonomy in conjunction with scientific freedom and research integrity.

\section{Privacy}

Privacy in military genomics may at once be a less compelling concern as regards information flows within the military and of heightened relevance for information flows outside of the military. As regards the former, it has been argued that genomic research should be 'strictly separated from the use of genetic information for operational purposes', for example, identification of remains or quality assurance purposes. ${ }^{8}$ Canadian civilian norms do not allow for the use of such residual samples without the explicit consent of the individual. ${ }^{5}$ Stored tissues and samples obtained as part of enlistment should thus not be used in genomic research.

As concerns information flows outside of the military, security measures are a central concern. For example, the reliance on public and semipublic cloud computing resources for the storage and analysis of genomic and health-related data poses challenges. Such data are considered 'protected category' data under norms from the Government of Canada, which requires that a cloud service provider 
be audited and certified to be eligible to provide services with respect to such protected data. $^{10}$

\section{Genetic discrimination}

With genomic research and its applications come concerns about genetic discrimination. The federal Genetic NonDiscrimination Act (GNDA) requires the written, informed and freely given consent of the proband before disclosing any genetic test results as a condition for entering into or continuing a contract, employment or otherwise. ${ }^{11}$ This is a significant difference from the USA, whose Genetic Information Nondiscrimination Act does not apply to the military. ${ }^{12}$ In practice, the GNDA means that any use of service members' genetic information must be voluntary. While not an issue for research, any further uses of genetic information in the operational context could not be mandatory. Indeed, service members cannot waive legal rights as part of their participation in research, nor does the conduct of research obviate the obligations that employers have to employees. ${ }^{3}$

By prohibiting the direct or indirect adverse differentiation of employees on the basis of genetic characteristics, the potential for the CAF to use genetic information for operational purposes such as deployment decisions is unclear. It remains possible to differentiate on the basis of genetic characteristics where it is a bona fide occupational requirement. Yet, the justificatory bar for genetic characteristics to qualify as such is likely high. It has been noted that many clinically significant genetic variants are not expected to affect service members when they are still asymptomatic. ${ }^{13}$ The potential to use genetic characteristics for non-research purposes thus remains relatively limited in light of the GNDA's protections.

\section{Return of results}

In Canada, 'material' results must be returned unless a research ethics board has approved a plan that does not foresee the return of results. As concerns the disclosure of incidental findings to research participants in Canada: 'Within the limits of consent provided by the participant, researchers shall disclose to the participant any material incidental findings discovered in the course of research'. Where material incidental findings are reasonably foreseeable, a protocol should be developed, which must be approved by a research ethics board. ${ }^{14}$

Further consideration should be given to how to contextualise the finding within the work of the service member. ${ }^{15}$ For example, it should be considered whether the finding may affect individual performance or if it may have consequences for broader activities within certain groups. We believe that further research into the psychosocial effects of disclosure of genetic test results to service members is required to potentially justify a departure from the civilian position regarding the return of results.

Before derogating from the civilian position concerning the return of material findings, we believe that evidence should suggest that there is a not-insignificant risk of materially affecting the performance of service members. Furthermore, a policy against returning would need to be proportionate to the potential harm that may be averted through disclosure. Consider the case where a junior recruit undergoes genomic sequencing and a clinically actionable material incidental finding is discovered. Where the consequences of not attending to the finding are either serious in the present or may become serious later in life, a strongly compelling justification should be required before potentially depriving this individual from being able to act on this information.

\section{CONCLUSION}

As genomics continues to further our understanding of the genetic determinants of human health and performance, its military applications are likely to increase. A central concern going forward is on the responsible, ethical design and conduct of genomic research with service members. A common theme among issues in consent, privacy, genetic discrimination and the return of results is the increased protections that ethics and law provide for service members participating in genomic research. These protections ensure that research conducted under the auspices of the Canadian military cohere with the fundamental values of Canadian society: respect for individuality, beneficence, privacy and no unjustified discrimination.

Contributors $C B$ conceptualised the research in collaboration with MJSB and BMK. MJSB conducted the research in consultation with BMK. MJSB drafted the manuscript with critical editing provided by BMK and $\mathrm{CB}$.

Funding This work was funded by Defence Research and Development Canada.

Competing interests MJSB and BMK are consultants to $C B$, who is an employee of Defence Research and Development Canada.

\section{Patient consent for publication Not required.}

Provenance and peer review Not commissioned; internally peer reviewed.

\section{(2) OPEN ACCESS}

Open access This is an open access article distributed in accordance with the Creative Commons Attribution Non Commercial (CC BY-NC 4.0) license, which permits others to distribute, remix, adapt, build upon this work non-commercially, and license their derivative works on different terms, provided the original work is properly cited, appropriate credit is given, any changes made indicated, and the use is non-commercial. See: http:// creativecommons.org/licenses/by-nc/4.0/.

(C) Author(s) (or their employer(s)) 2021. Re-use permitted under CC BY-NC. No commercial re-use. See rights and permissions. Published by BMJ.

\section{Check for updates}

To cite Beauvais MJS, Knoppers BM, Boscarino C. BMJ Mil Health Epub ahead of print: [please include Day Month Year]. doi:10.1136/ bmjmilitary-2021-001954

Accepted 7 August 2021

BMJ Mil Health 2021:0:1-3.

doi:10.1136/bmjmilitary-2021-001954

\section{ORCID iD}

M J S Beauvais http://orcid.org/0000-0002-8371-3836

\section{REFERENCES}

1 Maxwell MD, Hsu R, Islam R, et al. Educating military primary health-care providers in genomic medicine: lessons learned from the MilSeq project. Genet Med 2020:22:1710-7.

2 De Castro MJ, Turner CE. Military genomics: a perspective on the successes and challenges of genomic medicine in the armed services. Mol Genet Genomic Med 2017:5:617-20.

3 National Defence. DAOD 5061-0, Research Involving Human Subjects [Internet]. aem, 2013. Available: https://www.canada.ca/en/department-nationaldefence/corporate/policies-standards/defenceadministrative-orders-directives/5000-series/5061/ 5061-0-research-involving-human-subjects.html

4 Council for International Organizations of Medical Sciences. International ethical guidelines for healthrelated research involving humans. 4th edn. Geneva: CIOMS, 2016: i-122.

5 Canadian Institutes of Health Research, Natural Sciences and Engineering Research Council of Canada, Social Sciences and Humanities Research Council. TriCouncil policy statement: ethical conduct for research involving humans. Ottawa: Secretariat on Responsible Conduct of Research, 2018.

6 Mehlman MJ, Li TY. Ethical, legal, social, and policy issues in the use of genomic technology by the U.S. military. J Law Biosci 2014;1:244-80.

7 Spence DL. Ensuring respect for persons when recruiting junior enlisted personnel for research. Mil Med 2007:172:250-3.

8 Allyse M, Milner LC, Cho MK. Ethics Watch: the G.I. genome: ethical implications of genome sequencing in the military. Nat Rev Genet 2011;12:589.

9 De Castro M, Biesecker LG, Turner C, et al. Genomic medicine in the military. NPJ Genom Med 2016;1:1-4.

10 Government of Canada PW and GSC. Levels of security - Security screening for government contracts - Security requirements for contracting with the Government of Canada - Canada.ca [Internet], 2016. Available: https://www.tpsgc-pwgsc.gc.ca/esc-src/ protection-safeguarding/niveaux-levels-eng.htm 11 Genetic Non-Discrimination Act, SC 2017, c 3. 
12 Baruch S, Hudson K, Civilian HK. Civilian and military genetics: Nondiscrimination policy in a post-GINA world. Am J Hum Genet 2008;83:435-44.

13 Hellwig LD, Turner C, Manolio TA, et al. Return of secondary findings in genomic sequencing: military implications. Mol Genet Genomic Med 2019;7:e00483.

14 Ells C, Fernandez CV, Illes J. How to address material incidental findings: quidance in applying TCPS2 (2018) article 3.4. Ottawa, ON: Panel on Research Ethics of the Secretariat on Responsible Conduct of Research, 2019: 1-12.

15 Mehlman MJ, Parasidis E. Predictive genetic testing by the U.S. military: legal and ethical issues. Mil Med 2021;186:726-32. 